\title{
Regulation of the osteogenic and adipogenic differentiation of bone marrow-derived stromal cells by extracellular uridine triphosphate: The role of P2Y2 receptor and ERK1/2 signaling
}

\author{
WENKAI LI, SHENG WEI, CHAOXU LIU, MINGYU SONG, HUA WU and YONG YANG \\ Department of Orthopedics, Tongji Hospital, Tongji Medical College, Huazhong University \\ of Science and Technology, Wuhan 430030, P.R. China
}

Received June 30, 2015; Accepted October 20, 2015

DOI: $10.3892 / \mathrm{ijmm} .2015 .2400$

\begin{abstract}
An imbalance in the osteogenesis and adipogenesis of bone marrow-derived stromal cells (BMSCs) is a crucial pathological factor in the development of osteoporosis. Growing evidence suggests that extracellular nucleotide signaling involving the $\mathrm{P} 2$ receptors plays a significant role in bone metabolism. The aim of the present study was to investigate the effects of uridine triphosphate (UTP) on the osteogenic and adipogenic differentiation of BMSCs, and to elucidate the underlying mechanisms. The differentiation of the BMSCs was determined by measuring the mRNA and protein expression levels of osteogenic- and adipogenic-related markers, alkaline phosphatase (ALP) staining, alizarin red staining and Oil Red $\mathrm{O}$ staining. The effects of UTP on BMSC differentiation were assayed using selective P2Y receptor antagonists, small interfering RNA (siRNA) and an intracellular signaling inhibitor. The incubation of the BMSCs with UTP resulted in a dose-dependent decrease in osteogenesis and an increase in adipogenesis, without affecting cell proliferation. Significantly, siRNA targeting the $\mathrm{P} 2 \mathrm{Y} 2$ receptor prevented the effects of UTP, whereas the P2Y6 receptor antagonist (MRS2578) and siRNA targeting the P2Y4 receptor had little effect. The activation of P2Y receptors by UTP transduced to the extracellular signal-regulated kinase 1/2 (ERK1/2) signaling pathway. This transduction was prevented by the mitogen-activated protein kinase inhibitor (U0126) and siRNA
\end{abstract}

Correspondence to: Professor Hua Wu or Dr Yong Yang, Department of Orthopedics, Tongji Hospital, Tongji Medical College, Huazhong University of Science and Technology, 1095 Jiefang Avenue, Wuhan 430030, P.R. China

E-mail:wuhua360@aliyun.com

E-mail: yangyong0127@hotmail.com

Abbreviations: UTP, uridine triphosphate; BMSCs, bone marrowderived stromal cells; ERK1/2, extracellular signal-regulated kinase 1/2

Key words: uridine triphosphate, mesenchymal stem cells, osteogenesis, adipogenesis, purinergic P2Y2 receptor, extracellular signal-regulated kinase $1 / 2$ targeting the $\mathrm{P} 2 \mathrm{Y} 2$ receptor. U0126 prevented the effects of UTP on osteogenic- and adipogenic-related gene expression after $24 \mathrm{~h}$ of culture, as opposed to 3 to 7 days of culture. Thus, our data suggest that UTP suppresses the osteogenic and enhances the adipogenic differentiation of BMSCs by activating the P2Y2 receptor. The ERK1/2 signaling pathway mediates the early stages of this process.

\section{Introduction}

Osteoporosis is a systemic disease characterized by low bone mass, increased bone fragility and susceptibility to fracture (1). Although the detailed pathological mechanisms remain unknown, previous studies have suggested that the structural abnormalities associated with osteoporotic bones are attributable to the dysfunction of bone marrow-derived stromal cell (BMSC) differentiation (2-6). BMSCs are self-renewable, multipotent stem cells with the capacity to differentiate into lineages of mesenchymal tissues, such as chondrocytes, osteoblasts and adipocytes, when cultivated under appropriate conditions using specific hormonal inducers or growth factors $(7,8)$. Bone regeneration is a complex process mediated by the close association between the activities of osteogenic and adipogenic progenitor cells, which both derive from BMSCs $(7,8)$. The balance between the osteogenesis and adipogenesis of BMSCs can be disrupted. BMSCs have a reduced capacity to differentiate into osteoblasts, but an increased capacity for adipocyte differentiation. The increase in the proportion of fat in bone marrow subsequently induces the apoptosis of osteoblasts and the proliferation of osteoclasts, which results in further bone resorption and overall bone loss $(9,10)$.

Mechanical loads on bone tissue increase bone formation and improve bone strength (11). The removal of mechanical stimuli during immobilization or in microgravity results in a rapid loss of bone mass, whereas the application of exogenous mechanical loading leads to increased bone formation in the modeling skeleton (12). The molecular mechanisms mediating the conversion of mechanical stimuli into biochemical signaling remain poorly understood. Previous studies have suggested that extracellular nucleotides, such as adenosine 5'-triphosphate (ATP) and uridine triphosphate (UTP), are soluble factors released in response to mechanical stimulation in different cell 
types (13-15). Once released, extracellular nucleotides stimulate plasma membrane-localized nucleotide receptors: $\mathrm{P} 2$ receptors play a significant role in bone remodeling (16-18). Based on their molecular structure and activated signaling pathways, the $\mathrm{P} 2$ receptor family is divided into 2 subfamilies: the $\mathrm{P} 2 \mathrm{X}$ and $\mathrm{P} 2 \mathrm{Y}$ receptors (19). Currently, $7 \mathrm{P} 2 \mathrm{X}(\mathrm{P} 2 \mathrm{X} 1-7)$ and $8 \mathrm{P} 2 \mathrm{Y}$ (P2Y1, 2, 4, 6, 11, 12, 13 and 14) receptors have been identified, each of which has been cloned, characterized and assigned distinct tissue expression patterns and pharmacology. P2XRs are ligand-gated ion channels, whereas P2YRs are G proteincoupled receptors (20). The pattern of expression of different P2R subtypes on cell membranes influences the activity and the effects of nucleotides (20).

In particular, UTP stimulates the $\mathrm{P} 2 \mathrm{Y} 2$ and $\mathrm{P} 2 \mathrm{Y} 4$ receptors. In addition, UTP is hydrolyzed to uridine diphosphate (UDP), which acts on the P2Y6 receptor (21). UTP has been implicated in the regulation of osteogenesis in a number of cell types, including rat osteoblasts and human BMSCs. However, these results appear to demonstrate certain discrepancies: for example, UTP, but not ADP or UDP, promotes alkaline phosphatase (ALP) activity and bone mineralization, and increases the mRNA levels of ALP, bone morphogenetic protein (BMP)-2, BMP-4, BMP-5 and bone sialoprotein (BSP) through the P2Y2 receptor in rat primary ostoblasts (22). UTP and UDP facilitate the osteogenic differentiation of cells which is indicated by an increase in ALP activity through the activation of UDP-sensitive $\mathrm{P} 2 \mathrm{Y} 6$ receptors, but not through $\mathrm{P} 2 \mathrm{Y} 2$ and $\mathrm{P} 2 \mathrm{Y} 4$ receptors, in the BMSCs of post-menopausal women (17). A component of the inhibitory action of ATP and UTP on bone mineralization could thus be mediated directly by PPi, independently of P2 receptors (23). UTP, signaling via the $\mathrm{P} 2 \mathrm{Y} 2$ receptor on osteoblasts, blocks bone mineralization and bone formation $(24,25)$. The various physiological effects of UTP and P2Y receptors have also been studied in adipocytes. UTP and UDP have been shown to increase intracellular $\mathrm{Ca}^{2+}$ levels in brown adipocytes (26). UTP has also been shown to effectively elevate the intracellular calcium levels in white adipocytes via the $\mathrm{P} 2 \mathrm{Y} 2$ receptor, and the activation of the P2Y11 receptor inhibited leptin production and stimulated lipolysis (27). Based on the above-mentioned evidence, we hypothesized that UTP and P2Y receptors play a critical role in the osteogenic and adipogenic differentiation of BMSCs. Thus far, little is known about the expression of P2Y receptor subtypes and the potential effects of UTP on the differentiation process of rat BMSCs. Thus, in the present study, we aimed to determine whether UTP regulates the osteogenic and adipogenic differentiation of BMSCs and if so, to identity which of the $\mathrm{P} 2 \mathrm{Y}$ receptors mediate such a response, and to elucidate the underlying mechanisms.

\section{Materials and methods}

Reagents. Unless otherwise stated, all cell culture reagents were purchased from Gibco (Paisley, UK). TRIzol reagent was supplied by Invitrogen (Grand Island, NY, USA). ALP kits, alizarin red S, Oil Red O, UTP and MRS2578 (P2Y6 receptor antagonist; $1 \mu \mathrm{M}$ was added to the cell cultures $1 \mathrm{~h}$ prior to UTP treatment) were obtained from Sigma-Aldrich (St. Louis, MO, USA). U0126 [a mitogen-activated protein kinase inhibitor (MAPK; $5 \mu \mathrm{M}$ were added to the cell cultures $1 \mathrm{~h}$ prior to UTP treatment)] was procured from Beyotime Institute of Biotechnology (Shanghai,
China). Lipofectamine 3000 was purchased from Invitrogen. Rat mesenchymal stem cell (MSC) adipogenic and osteogenic differentiation medium were purchased from Cyagen Biosciences Inc. (Santa Clara, CA, USA).

BMSC culture. Rat BMSCs were isolated from 4-week-old male Sprague-Dawley (SD) rats and expanded in accordance with previously published techniques (28). All animal experiments were approved by the Animal Care and Use Committee for Teaching and Research, of Huazhong University of Science and Technology (Wuhan, China). The cells were maintained in expansion medium, consisting of Dulbecco's modified Eagle's medium/F12 (1:1) and 10\% fetal bovine serum (FBS) supplemented with $100 \mathrm{U} / \mathrm{ml}$ penicillin and $100 \mathrm{U} / \mathrm{ml}$ streptomycin, in a humidified atmosphere containing $5 \% \mathrm{CO}_{2}$. Upon reaching confluence, the cells were detached with $0.25 \%$ trypsin (Boster Inc., Wuhan, China) and passaged at a ratio of 1:2. BMSCs of passages 3-5 were used in the experiments. Cells maintained in expansion medium were used as undifferentiated cells. To induce osteogenic differentiation, the cells were cultured in osteogenic differentiation medium (10 $\mathrm{nM}$ dexamethasone, $50 \mu \mathrm{g} / \mathrm{ml}$ ascorbic acid and $10 \mathrm{mM}$ $\beta$-glycerophosphate in expansion medium) supplemented with UTP for 21 days. The medium was changed every 3 days.

CCK-8 proliferation assay. The cells were seeded in 96-well plates at a density of $2 \times 10^{3}$ cells/well, and divided into 4 groups as follows: the control (without any treatment), and the cells treated with 5, 25 and $125 \mu \mathrm{M}$ UTP, respectively. Each group comprised 5 sub-wells. Cell proliferation was assessed by CCK-8 (Beyotime Institute of Biotechnology) assay, after processing for $0,24,48$ and $72 \mathrm{~h}$. Briefly, $10 \mu \mathrm{l} \mathrm{CCK-8} \mathrm{solution}$ were added to each well followed by incubation in the dark for $1.5 \mathrm{~h}$ and the absorbance was then read using a microplate reader (Sunrise RC; Tecan, Mannedorf, Switzerland) at $450 \mathrm{~nm}$.

Total RNA extraction and quantitative PCR ( $q P C R)$. Total RNA was extracted using TRIzol reagent. The purity and concentration of the RNA samples were determined spectroscopically. First-strand cDNA was synthesized from $3 \mu \mathrm{g}$ RNA, using an EasyScript First-Strand cDNA synthesis super mix kit (TransGen Biotech Co., Ltd., Beijing, China) and used for qPCR. The expression of runt-related transcription factor 2 (RUNX2), ALP and osteopontin (OPN) was quantified using a Bio-Rad MyiQ2 sequence detection system and TransStart Eco Green qPCR SuperMix (TransGen Biotech Co., Ltd.). The primers were synthesized by Invitrogen, and their sequences are listed in Table I. The reactions were incubated at $95^{\circ} \mathrm{C}$ for $30 \mathrm{sec}$, followed by 40 cycles of $94^{\circ} \mathrm{C}$ for $5 \mathrm{sec}$ and $60^{\circ} \mathrm{C}$ for $35 \mathrm{sec}$. The relative expression of gene-specific products was analyzed using the $2^{-\Delta \Delta \mathrm{Ct}}$ method and normalized to the corresponding GAPDH values.

ALP staining and quantification. The cells were seeded at a density of $10^{5}$ cells/well in $35-\mathrm{mm}$ plastic dishes with or without UTP $(125 \mu \mathrm{M})$ in osteogenic medium. After 7 days, ALP staining was performed using ALP kits. Briefly, after discarding the medium, the cells were gently washed with PBS 3 times and fixed with $4 \%$ paraformaldehyde for $15 \mathrm{~min}$ at $4^{\circ} \mathrm{C}$. The cells were washed with deionized water and then 
Table I. List of specific primers used in the present study.

\begin{tabular}{lll}
\hline Gene & \multicolumn{1}{c}{ Forward $\left(5^{\prime} \rightarrow 3^{\prime}\right)$} & \multicolumn{1}{c}{ Reverse $\left(5^{\prime} \rightarrow 3^{\prime}\right)$} \\
\hline GAPDH & GGCACAGTCAAGGCTGAGAATG & ATGGTGGTGAAGACGCCAGTA \\
RUNX2 & GCACCCAGCCCATAATAGA & TTGGAGCAAGGAGAACCC \\
PPAR $\gamma$ & CCTTTACCACGGTTGATTTCTC & GGCTCTACTTTGATCGCACTTT \\
ALP & CAAGGACCAACTACAACCA & AGGGAAGGGTCAGTCAGGTT \\
OPN & CCTGGACCTCATCAGCATTT & GGAGAC AGGAGGCAAGG \\
Adipsin & CACGTGTGCGGTGGCACCCTG & CCCCTGCAAGTGTCCCTGCGGT \\
Fabp4 & GCGTAGAAGGGGACTTGGTC & TTCCTGTCATCTGGGGTGATT
\end{tabular}

RUNX2, runt-related transcription factor 2; ALP, alkaline phosphatase; OPN, osteopontin; PPAR $\gamma$, peroxisome proliferator-activated receptor $\gamma$; FABP4, fatty acid binding protein 4

stained with naphthol AS-MX phosphate for $30 \mathrm{~min}$ in the dark and washed 3 times with PBS. Images were acquired using a light microscope (Eclipse Ti; Nikon, Tokyo, Japan). Image-Pro Plus 5.0 was used to analyze the quantity of the dyed areas.

Alizarin red Staining and quantification. The cells were cultured in osteogenic medium in 35-mm plastic dishes for 21 days with or without UTP $(125 \mu \mathrm{M})$. Briefly, the cells were washed with PBS and fixed with $4 \%$ paraformaldehyde, for $30 \mathrm{~min}$ at room temperature. After washing with deionized water, the fixed cells were stained with $2 \%$ alizarin red $\mathrm{S}(\mathrm{pH} 4.2)$ in deionized water. After $20 \mathrm{~min}$, the cells were washed with deionized water and observed under a light microscope (Eclipse Ti; Nikon). Image-Pro Plus 5.0 was used to quantify the nodule areas.

Oil Red $O$ staining and quantification. To induce adipogenic differentiation, the BMSCs were seeded at $2 \times 10^{4}$ cells $/ \mathrm{cm}^{2}$ on $35-\mathrm{mm}$ plastic dishes and grown for 3 days in adipogenic induction medium (Cyagen Biosciences, Inc.) containing additional SD rat MSC adipogenic differentiation basal medium A, FBS, insulin, glutamine, rosiglitazone, dexamethasone, 3-isobutyl-1-methylxanthine and penicillin/streptomycin, followed by 1 day in adipogenic maintenance medium containing SD rat MSC adipogenic differentiation basal medium A, FBS, insulin, glutamine and penicillin/streptomycin (1 cycle). Both steps were repeated up to day 21 (indicated as the 5 th cycle), when the cell culture was terminated for Oil Red $\mathrm{O}$ staining. UTP $(125 \mu \mathrm{M})$ was added to the culture medium every 3 days. Briefly, the cells were washed with PBS and fixed with $4 \%$ paraformaldehyde, for $30 \mathrm{~min}$ at room temperature. After washing with PBS, the fixed cells were stained with Oil Red O in deionized water. After $20 \mathrm{~min}$, the cells were washed with PBS twice and observed under a light microscope (Eclipse Ti; Nikon). Image-Pro Plus 5.0 was used to quantify the nodule areas.

Western blot analysis. The cells were lysed using the protein extraction reagent RIPA supplement, with protease and phosphatase inhibitor and phenylmethylsulfonyl fluoride (all from Beyotime Institute of Biotechnology). Cell homogenates were sonicated for $5 \mathrm{~min}$ and protein concentrations from the lysates were determined by BCA protein assay (Boster Inc.). Prior to loading, total protein samples were denatured by incubation at $95^{\circ} \mathrm{C}$ for $5 \mathrm{~min}$ in the presence of $5 \mathrm{X}$ reducing sample buffer (60 mM Tris- $\mathrm{HCl}$ pH 6.8, 25\% glycerol, $2 \%$ SDS, $10 \% \beta$-mercaptoethanol and $0.1 \%$ bromophenol blue). Thirty micrograms of protein sample were separated by SDS-polyacrylamide gel electrophoresis and transferred onto polyvinylidene fluoride (PVDF) membranes. Following incubation in 5\% BSA at room temperature, the membranes were incubated with rabbit anti-total-ERK1/2 antibody $(1: 1,000$; Cat. no. 4695P; Cell Signaling Technology, Inc., Beverly, MA, USA), rabbit anti-p-ERK1/2 antibody (1:1,000; Cat. no. 4377S; Cell Signaling Technology, Inc.), rabbit anti-total-JNK antibody (1:1000; Cat. no. 9252S; Cell Signaling Technology, Inc.), rabbit anti-p-JNK antibody (1:1,000; Cat. no. 4668T; Cell Signaling Technology, Inc.), rabbit anti-total-p38 antibody (1:1,000; Cat. no. 8690P; Cell Signaling Technology, Inc.), mouse anti-p-p38 antibody (1:1,000; Cat. no. 9216S; Cell Signaling Technology, Inc.), mouse anti-GAPDH antibody (1:5,000; Cat. no. BM1623; Boster Inc.), mouse anti-RUNX2 antibody (1:400; Cat. no. ab76596; Abcam, Cambridge, UK), rabbit anti-ALP antibody (1:1,000; Cat.no. ab133602; Abcam), mouse anti-OPN antibody (1:500; Cat. no. ab69498; Abcam), rabbit anti-PPAR $\gamma$ antibody (1:400; Cat. no. ab133602; Abcam), rabbit anti-FABP4 antibody (1:1,000; Cat. no. ab92501; Abcam), goat anti-adipsin antibody (1:400; Cat. no. sc12403; Santa Cruz Biotechnology, Inc., CA, USA) at $4^{\circ} \mathrm{C}$ overnight. Anti-mouse horseradish peroxidase (HRP)-conjugated IgG $(1: 5,000$; Cat. no. 7076P2) and anti-rabbit HRP-conjugated $\operatorname{IgG}(1: 5,000$; Cat. no. 7074P2; both from Cell Signaling Technology, Inc., Beverly, MA, USA) were used as the secondary antibodies. The immunostained protein bands were detected by chemiluminescence. Protein levels were determined by normalizing to GAPDH.

Gene silencing by small interfering RNA (siRNA). Scrambled siRNA, P2Y2 siRNA and P2Y4 siRNA were designed and synthesized by RiboBio (Guangzhou, China). According to the manufacturer's instructions (RiboBio and Invitrogen), BMSCs were seeded on 6-well plates at a density of $5 \times 10^{4}$ cells/well in normal medium and grown to $70-90 \%$ confluence prior to transfection. A transfection mixture containing Lipofectamine 3000 (7.5 $\mu \mathrm{l} /$ well; Invitrogen) and $100 \mathrm{nM}$ siRNA targeting P2Y2 or P2Y4 receptor or scrambled siRNA 
(all from RiboBio) sequence was prepared in $250 \mu 1$ Opti-MEM (Invitrogen) and incubated for $5 \mathrm{~min}$ at room temperature. After being washed with Opti-MEM, the cells were incubated with the transfection mixture in 1,750 $\mu$ l Opti-MEM for 4 days at $37^{\circ} \mathrm{C}$. The effects of gene silencing were determined by qPCR at 24, 48, 72 and $96 \mathrm{~h}$ following transfection.

Immunofluorescence staining. Rat BMSCs were seeded onto sterile 1 -cm-diameter discs in 24 -well trays at $2.5 \times 10^{4}$ cells/disc for 5 days. The discs were removed and fixed with $4 \%$ paraformaldehyde for $15 \mathrm{~min}$ at room temperature; after washing 3 times with PBS, the cells were blocked for $1 \mathrm{~h}$ with PBS containing 5\% FBS. The samples were then incubated overnight at $4^{\circ} \mathrm{C}$ with anti-P2Y2 (1:200; Cat. no. ab10270; Abcam) primary antibody, washed 3 times with PBS and incubated for $1 \mathrm{~h}$ at room temperature with the goat anti-rabbit Cy3-labelled secondary antibody solution (1:500; Cat. no. AB6939; Abcam) diluted in blocking solution. The cells were further counterstained with DAPI (1:3,000; Cat. no. AR1176; Boster Inc.). Fluorescent images were obtained with an inverted fluorescent microscope (Eclipse Ti; Nikon). Cy3 absorbance and emission at 552 and $565 \mathrm{~nm}$, and DAPI absorbance and emission at 360 and $460 \mathrm{~nm}$, respectively were assessed.

Statistical analysis. The results are expressed as the means \pm SD $(n=3)$. Statistical comparisons were performed using one-way ANOVA, followed by Tukey's post hoc test, which was carried out using SPSS 19.0 software. A P-value $<0.05$ was considered to indicate a statistically significant difference.

\section{Results}

UTP decreases the expression of osteogenic-related markers and increases the expression of adipogenic-related markers in undifferentiated BMSCs. BMSCs were cultured in expansion medium, with various concentrations of UTP (5-125 $\mu \mathrm{M})$, for 7 days. The expression levels of osteogenic- and adipogenicrelated markers were measurd by qPCR and western blot analysis. As shown in Fig. 1A and B, UTP decreased RUNX2, ALP and OPN mRNA and protein expression and increased peroxisome proliferator-activated receptor $\gamma$ (PPAR $\gamma$ ), fatty acid binding protein 4 (FABP4) and adipsin mRNA and protein expression in a dose-dependent manner.

The number of cells was measured using a CCK-8 kit, in order to examine the effects of UTP on the proliferation of BMSCs. As shown in Fig. 1B, no significant differences in the numbers of cells were observed (Fig. 1C), indicating that UTP affected the differentiation potential of BMSCs and was not cytotoxic. The concentration of $125 \mu \mathrm{M}$ UTP did not affect the proliferation of the BMSCs, but had the maximum effect on differentiation, and was therefore used in the following experiments.

UTP inhibits the osteogenic and enhances the adipogenic differentiation of stimulated BMSCs. To determine the effects of UTP on the differentiation of BMSCs into osteoblasts, the cells were cultured in osteogenic medium, with or without UTP $(125 \mu \mathrm{M})$ treatment for 7 days. The expression levels of osteogenic- and adipogenic-related markers were measured by qPCR and western blot analysis. As shown in Fig. 2A and B, the osteogenic medium-induced upregulation of RUNX2, ALP and OPN mRNA and protein expression was significantly reduced by UTP treatment.

Extracellular matrix mineralization was measured using alizarin red staining when the BMSCs were treated with UTP in osteogenic medium for 21 days. The BMSCs formed abundant characteristic nodules in the control cultures, and the number of these nodules was markedly decreased in the UTP-treated cultures (Fig. 2C). Thus, our data suggest that ALP plays a key role in bone mineralization. The effects of UTP on ALP expression were also examined at 7 and 21 days of culture in osteogenic medium. UTP inhibited ALP expression compared to the controls both at 7 and 21 days of culture (Fig. 2C).

We then examined the effects of UTP on the adipogenic differentiation of BMSCs. The BMSCs were cultured in adipogenic medium with or without UTP. As shown in Fig. 2D and E, UTP increased the mRNA and protein expression levels of PPAR, FABP4 and adipsin compared to the control on day 7. After 3 weeks of adipogenic differentiation, numerous lipid drops were observed in the intracellular spaces of the differentiated cells. The lipid content of the cells was demonstrated by Oil Red O staining; lipid accumulation was more evident in the UTP-treated cells compared to the untreated cell cultures (Fig. 2F).

$U T P$ regulates the osteogenic and adipogenic differentiation of BMSCs via the P2Y2 receptor. UTP stimulates the $\mathrm{P} 2 \mathrm{Y} 2$ and $\mathrm{P} 2 \mathrm{Y} 4$ receptors. In addition, UTP is hydrolyzed to UDP, which acts on the P2Y6 receptor (28). Thus, to identify which of the $\mathrm{P} 2 \mathrm{Y}$ receptor subtypes is associated with the effects of UTP on BMSCs, we added the selective P2Y6 receptor antagonist, MRS2578 $(1 \mu \mathrm{M})(29,30)$, to the cell cultures $1 \mathrm{~h}$ prior to UTP treatment. We observed that the effects of UTP + MRS2578 on osteogenic- and adipogenic-related gene expression were similar to those observed wtih UTP treatment (Fig. 3A), suggesting that the effects of UTP on BMSCs are mediated via $\mathrm{P} 2 \mathrm{Y} 2$ or $\mathrm{P} 2 \mathrm{Y} 4$ receptors rather than the $\mathrm{P} 2 \mathrm{Y} 6$ receptor.

A number of previous studies have reported that UTP inhibits bone mineralization in vitro via the $\mathrm{P} 2 \mathrm{Y} 2$ receptor in rat primary osteoblasts $(23-25,31)$. To determine whether the effects induced by UTP are mediated through the P2Y2 receptor, we employed siRNAs targeting the P2Y2 and P2Y4 receptor genes. The $\mathrm{P} 2 \mathrm{Y} 2$ and $\mathrm{P} 2 \mathrm{Y} 4$ siRNA silencing efficiency were both $85 \%$ at 2 days following transfection (data not shown). To examine the effects of P2Y2 and P2Y4 siRNA on BMSC differentiation, the cells were incubated with the transfection mixture for 2 days. Subsequently, the transfection mixture was replaced with osteogenic or adipogenic medium with UTP $(125 \mu \mathrm{M})$ and the cells were cultured for 5 days. Total RNA extraction and qPCR were then performed to determine the expression of osteogenic- and adipogenic-related genes. We found that P2Y2 siRNA prevented the downregulation of osteogenic-related gene expression and the upregulation of adipogenic-related genes induced by UTP, whereas P2Y4 receptor siRNA did not have a marked effect on the expression of these genes (Fig. 3B).

Effect of BMSC differentiation on the expression of $\mathrm{P} 2 \mathrm{Y} 2$ receptor. We first confirmed that the $\mathrm{P} 2 \mathrm{Y} 2$ receptor was expressed by rat BMSCs using immunofluorescence 

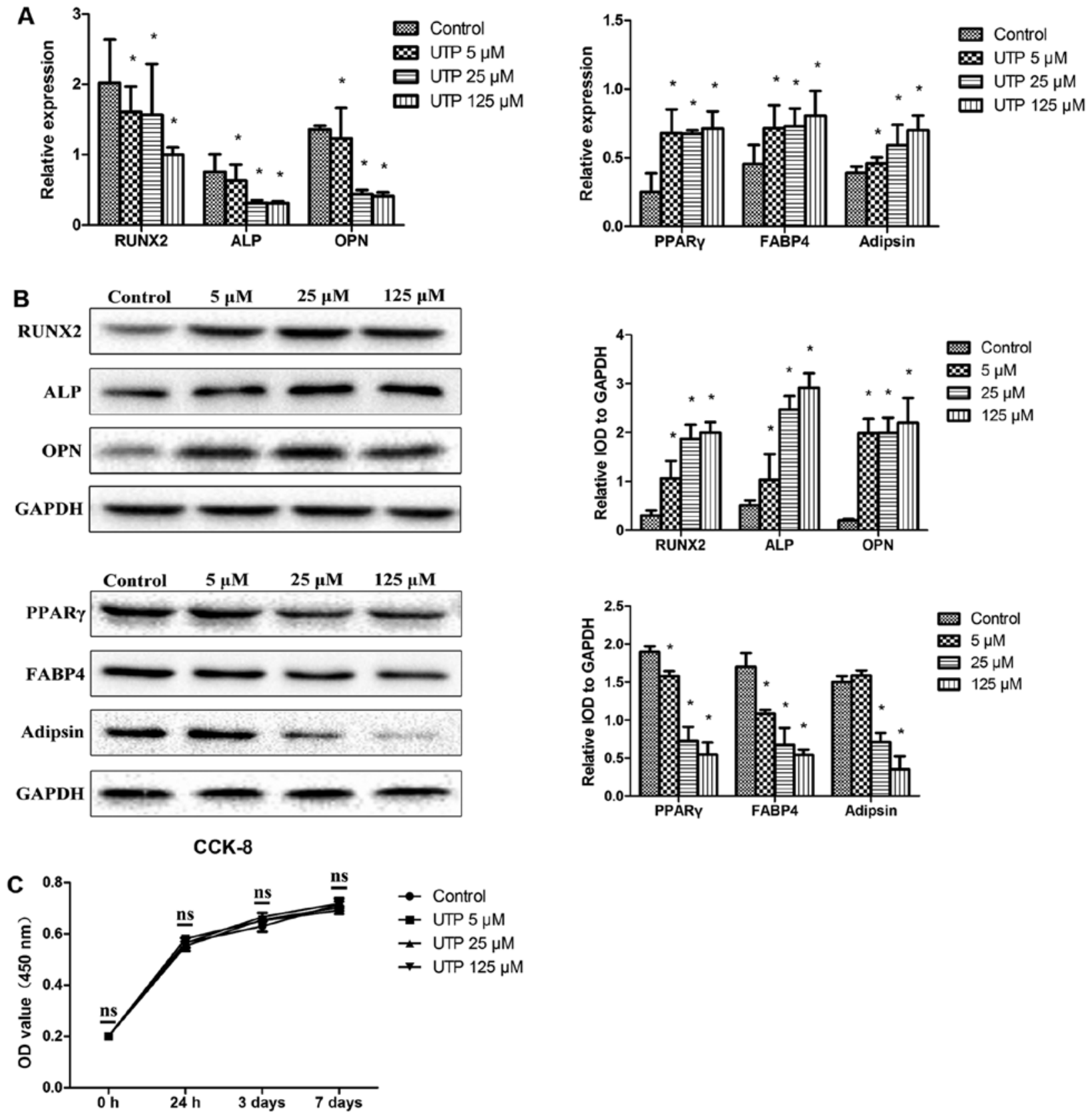

Figure 1. Effect of uridine triphosphate (UTP) on osteogenic- and adipogenic-related gene expression in undifferentiated bone marrow-derived stromal cells (BMSCs). UTP decreased osteogenic-related (A) gene and (B) protein expression and increased adipogenic-related (A) gene and (B) protein expression in a dose-dependent manner. Results are expressed as percentages with respect to GAPDH expression. Data represent the means $\pm \mathrm{SD}, \mathrm{n}=3$, ${ }^{*} \mathrm{P}<0.05$ vs. control. (C) A CCK-8 assay was used to measure the proliferation of BMSCs at different time points ( 0 and $24 \mathrm{~h}$, and 3 and 7 days). UTP did not affect the proliferation of BMSCs. Data represent the means $\pm \mathrm{SD}, \mathrm{n}=3$, not significant (ns) $\mathrm{P}>0.05$ vs. control. IOD, integrated optical density.

staining (Fig. 4A). P2Y2 receptor expression was evaluated by qPCR, in both stimulated (osteogenic and adipogenic medium) and unstimulated (expansion medium) BMSCs, with or without UTP treatment, on days 0, 3 and 7. As shown in Fig. 4B, in the cells cultured in adipogenic medium, the mRNA expression of the P2Y2 receptor increased on days 3 and 7 compared to day 0 . However, the mRNA expression of the P2Y2 receptor in the cells cultured in osteogenic medium decreased on days 3 and 7 compared to day 0 . Furthermore, UTP treatment failed to affect the expression of the P2Y2 receptor in both the osteogenic and adipogenic media. P2Y2 receptor expression remained relatively unaltered in the unstimulated cells.
UTP activates the ERK1/2 signaling pathway in BMSCs. MAPKs have been shown to be important in the differentiation of a number of cell types, including BMSCs (32-38). Thus, in this study, we examined the effects of treatment with UTP on the phosphorylation of 3 members of the MAPK family in rat BMSCs. As shown in Fig. 5A, of the 3 MAPK isoforms, only ERK1/2 was significantly phosphorylated following treatment with UTP. Maximal ERK1/2 activation was observed at $5 \mathrm{~min}$ and remained activated for up to $60 \mathrm{~min}$. Furthermore, U0126 (5 $\mu \mathrm{M})$, a selective MAPK inhibitor, completely abolished the phosphorylation of ERK1/2 induced by UTP (Fig. 5B). P2Y2 receptor siRNA was also used to suppress 
A

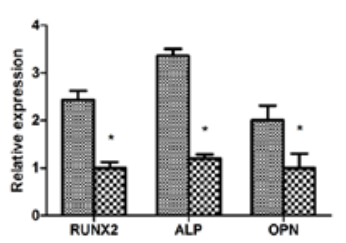

B

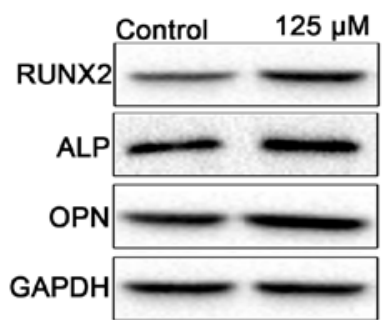

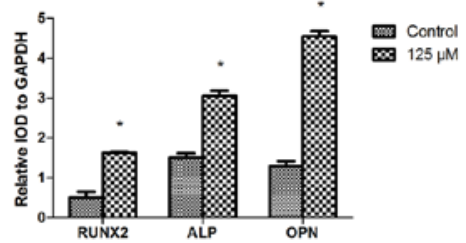

7 Days

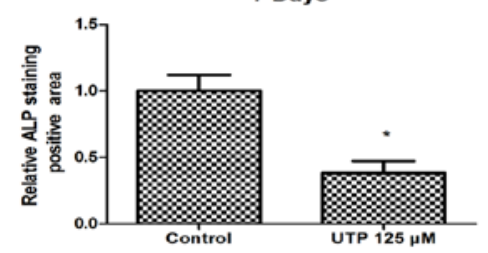

21 Days
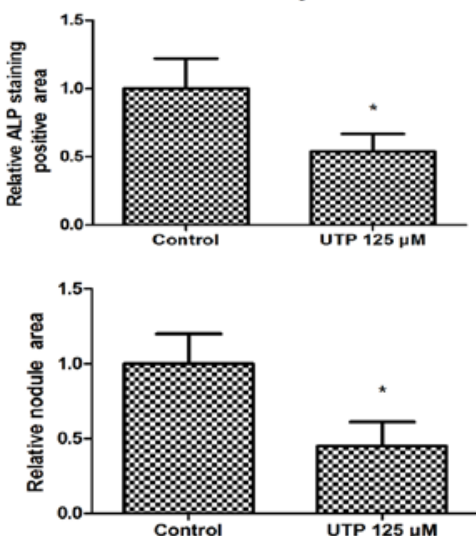

D



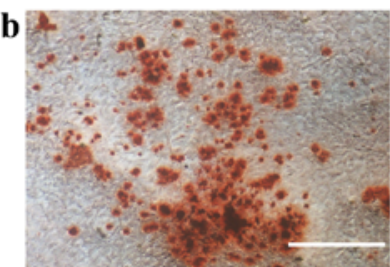
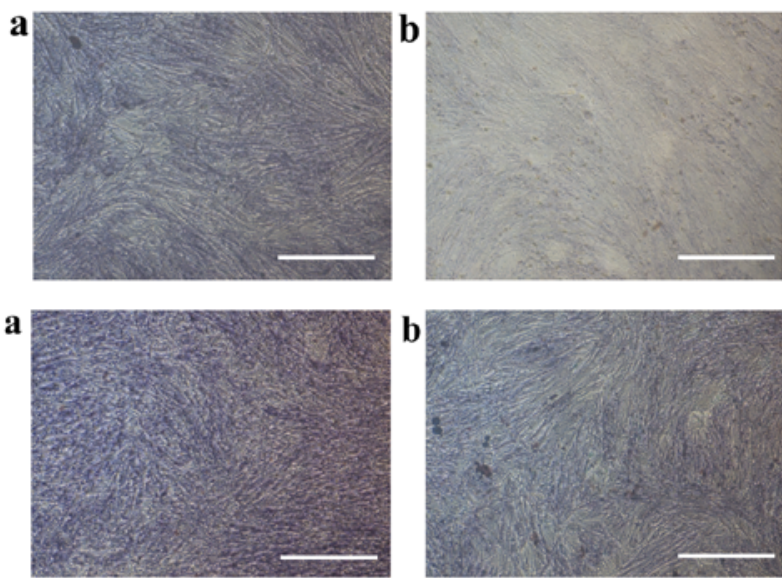

$E$
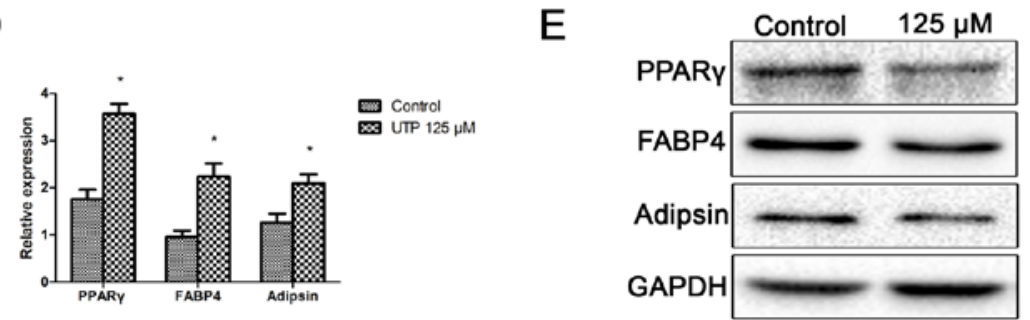

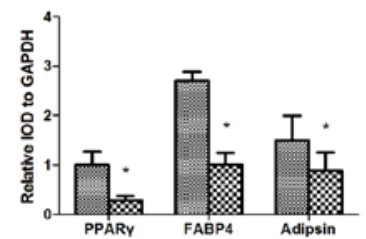

Control
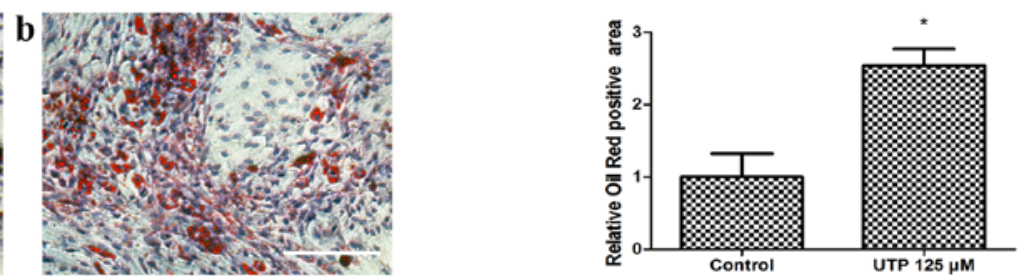

Figure 2. Uridine triphosphate (UTP) inhibits the osteogenic and enhances the adipogenic differentiation of stimulated bone marrow-derived stromal cells (BMSCs). Osteogenic medium-induced upregulation of osteogenic-related (A) mRNA and (B) protein expression was significantly reduced by UTP $(125 \mu \mathrm{M})$ treatment. Results are expressed as percentages with respect to GAPDH expression. Data represent the means $\pm \mathrm{SD}, \mathrm{n}=3$, ${ }^{*} \mathrm{P}<0.05$ vs. control. (C) Representative images and semi-quantitative analysis of alkaline phosphatase (ALP) staining [7 days (upper panel) and 21 days (middle panel)] and alizarin red S staining (lower panel). Bar, $50 \mu \mathrm{m}$; panels a, control; panels b, UTP $125 \mu \mathrm{M}$. Data represent the means $\pm \mathrm{SD}, \mathrm{n}=3$, ${ }^{*} \mathrm{P}<0.05$ vs. control. UTP increased adipogenic-related (D) mRNA and (E) protein expression compared to control in BMSCs cultured in adipogenic medium. Results are expressed as percentages with respect to GAPDH expression. Data represent the means $\pm \mathrm{SD}, \mathrm{n}=3,{ }^{*} \mathrm{P}<0.05$ vs. control. (F) Representative images and semi-quantitative analysis of Oil Red O staining. Bar, $50 \mu \mathrm{m}$; panel a, control; panel b, UTP $125 \mu \mathrm{M}$. Data represent the means $\pm \mathrm{SD}, \mathrm{n}=3$, $\mathrm{P}<0.05$ vs. control.

receptor expression in order to examine its role in ERK1/2 phosphorylation. UTP-induced ERK1/2 phosphorylation was attenuated by approximately $90 \%$ when the cells were treated with P2Y2 siRNA (Fig. 5B).
Role of the ERK1/2 signaling pathway in the osteogenic and adipogenic differentiation of BMSCs induced by UTP. To determine the role of ERK1/2 in the differentiation of BMSCs, we assessed the effects of UTP on osteogenic- and adipogenic- 

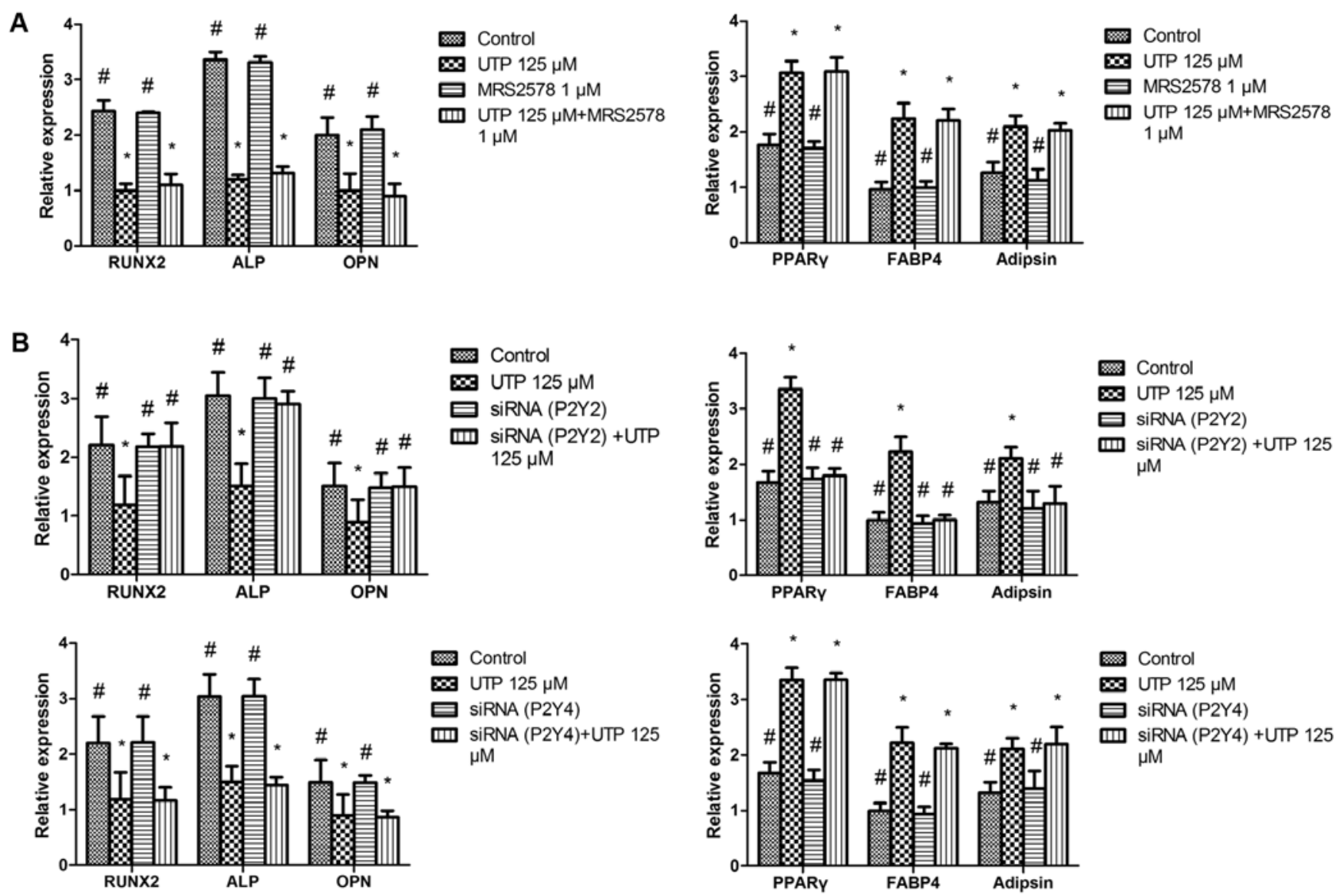

Figure 3. Uridine triphosphate (UTP) regulates the osteogenic and adipogenic differentiation of bone marrow-derived stromal cells (BMSCs) via the P2Y2 receptor. (A) Effects of UTP + MRS2578 on osteogenic- and adipogenic-related gene expression were similar to those observed with UTP treatment. Results are expressed as percentages with respect to GAPDH expression. Data represent the means $\pm \mathrm{SD}, \mathrm{n}=3,{ }^{*} \mathrm{P}<0.05$ vs. control, ${ }^{\prime \prime} \mathrm{P}<0.05$ vs. $\mathrm{UTP}(125 \mu \mathrm{M})$. (B) siRNA suppressed P2Y2 receptor expression, and prevented the downregulation of osteogenic gene expression and upregulation of adipogenic-related genes induced by UTP, whereas P2Y4 receptor siRNA did not have a marked effect on the expression of these genes. Results are expressed as percentages with respect to GAPDH expression. Data represent the means $\pm \mathrm{SD}, \mathrm{n}=3,{ }^{*} \mathrm{P}<0.05$ vs. control, ${ }^{\#} \mathrm{P}<0.05$ vs. UTP $(125 \mu \mathrm{M})$.


Figure 4. Effect of bone marrow-derived stromal cell (BMSC) differentiation on the expression of P2Y2 receptor. (A) Expression of the P2Y2 receptor by rat BMSCs. Cells were fixed and stained with anti-P2Y2 conjugated-secondary antibodies (red), and cell nuclei were counterstained with DAPI (blue). Scale bar, $50 \mu \mathrm{m}$. (B) qPCR of P2Y2 receptor expression during osteogenic and adipogenic differentiation of BMSCs. Results are expressed as percentage with respect to GAPDH expression. Data represent the means $\pm \mathrm{SD}, \mathrm{n}=3,{ }^{*} \mathrm{p}<0.05$ vs. expansion medium. 
A
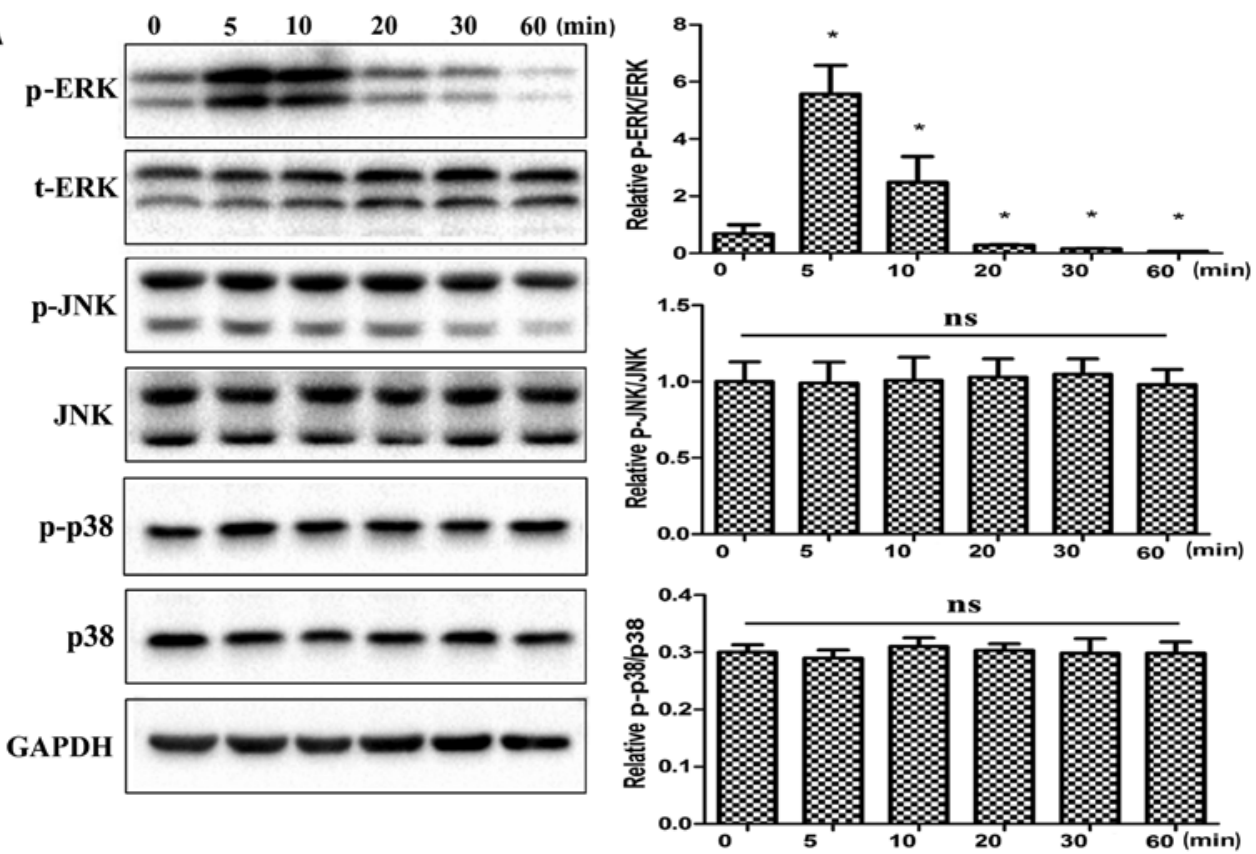

B
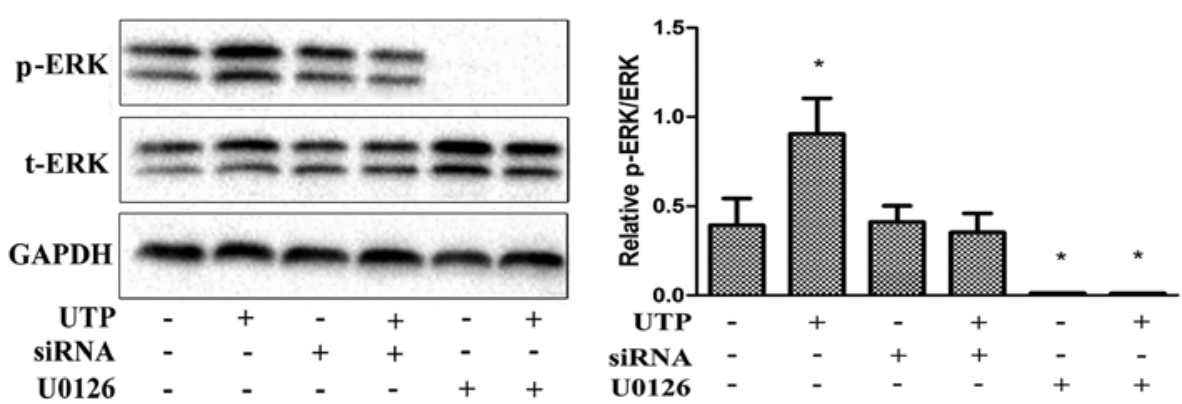

Figure 5. Representative images and semi-quantitative analysis of uridine triphosphate (UTP)-induced activation of MAPK signaling pathway. (A) Of the 3 MAPK isoforms, only extracellular signal-regulated kinase 1/2 (ERK1/2) was significantly phosphorylated following treatment with UTP. Data represent the means $\pm \mathrm{SD}, \mathrm{n}=3,{ }^{*} \mathrm{P}<0.05$ vs. 0 min, not significant (ns), P $>0.05$ vs. 0 min. (B) The UTP-induced ERK1/2 phosphorylation was blocked by U0126 and P2Y2 receptor siRNA. Data represent the means $\pm \mathrm{SD}, \mathrm{n}=3,{ }^{*} \mathrm{P}<0.05$ vs. (UTP-, siRNA- and U0126-).

related gene expression in BMSCs in the presence or absence of U0126 $(5 \mu \mathrm{M})$. UTP significantly inhibited osteogenic-related gene expression and increased adipogenic-related gene expression. These effects were significantly attenuated by U0126 in the cells cultured for $24 \mathrm{~h}$ (Fig. 6A). However, U0126 failed to prevent the effects induced by UTP on 3- and 7-day-old cell cultures (Fig. 6B). In addition, U0126 and U0126 + UTP induced the downregulation of osteogenic-related genes and the upregulation of adipogenic-related genes compared with the controls on days 3 and 7.

\section{Discussion}

This study demonstrated that, in relation to BMSCs, UTP inhibited osteogenesis and enhanced adipogenesis, without affecting cell growth. Furthermore, we confirmed that these effects induced by UTP acted via P2Y2 receptors. We also demonstrated that ERK1/2 signaling played differential roles in the differentiation of BMSCs. These findings help to broaden our understanding of the role of purinergic receptors, particularly the $\mathrm{P} 2 \mathrm{Y} 2$ receptor, in the functional differentiation of BMSCs.

It has previously been demonstrated that extracellular UTP exerts profound inhibitory effects on the bone mineralization mediated by P2Y receptors in primary osteoblasts (23-25). In the present study, we analyzed the molecular pathway activated by extracellular UTP during the BMSC differentiation process. Our findings revealed that the ability of UTP to modulate the differentiation of BMSCs into the osteoblastic lineage is relevant at a physiological level, as the number of mineralized nodules and ALP expression induced by culture in osteogenic medium were markedly reduced in UTP-treated cell cultures. Furthermore, UTP also decreased osteogenic-related mRNA and protein expression in unstimulated BMSCs, indicating that UTP may prevent precursor cells from differentiating into osteoblasts, and also inhibited extracellular matrix mineralization in osteoblasts differentiated from BMSCs. Few studies have, however, reported different results. It has previously been noted that UTP stimulated BMP gene expression and mineralization in rat primary osteoblasts (22), and enhanced the osteogenic differentiation of BMSCs obtained from postmenopausal women (17). We suggest that differences between cell types, osteogenic culture systems and variable methods for detecting osteogenic differentiation contribute to explaining the discrepancies. For example, first, osteoblasts from Wistar rats and BMSCs from post-menopausal women were used in these studies, whereas in the present study, we used BMSCs from 
A

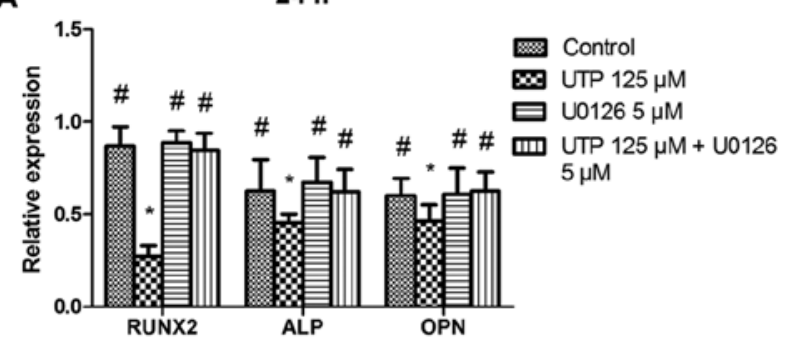

B

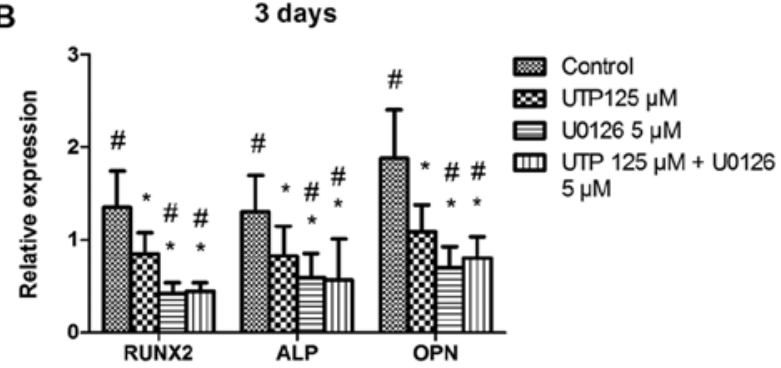

7 days

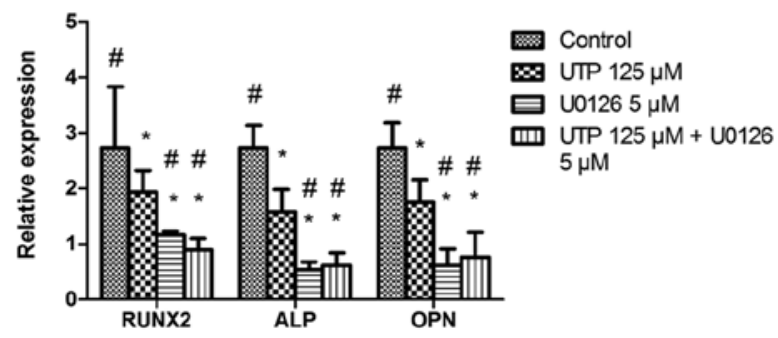

$24 \mathrm{~h}$

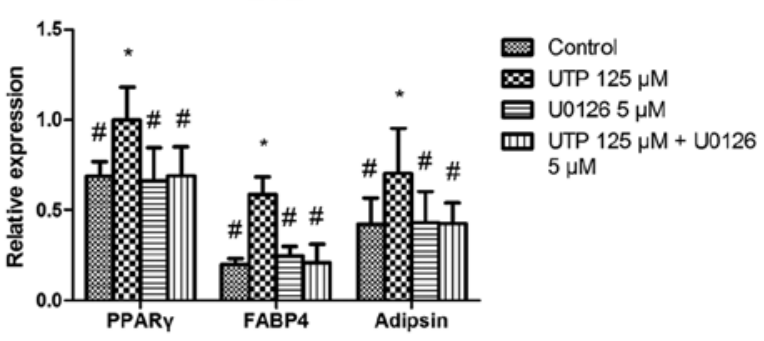

3 days

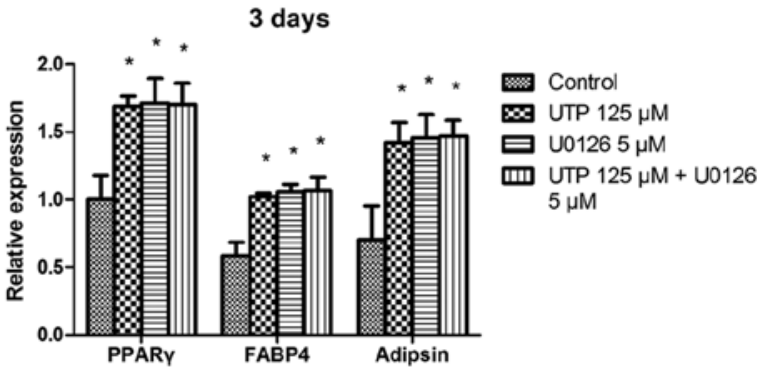

7 days

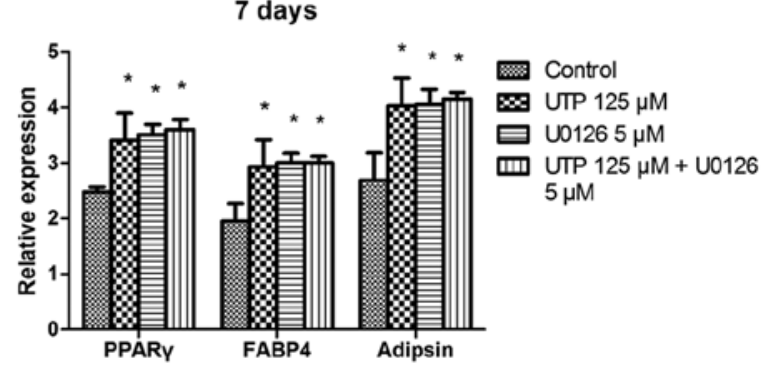

Figure 6. Role of extracellular signal-regulated kinase 1/2 (ERK1/2) signaling in osteogenic and adipogenic differentiation of bone marrow-derived stromal cells (BMSCs) induced by uridine triphosphate (UTP). (A) Effect of UTP on osteogenic- and adipogenic-related gene expression was significantly attenuated by U0126 following $24 \mathrm{~h}$ of culture. Results are expressed as percentages with respect to GAPDH expression. Data represent the means $\pm \mathrm{SD}, \mathrm{n}=3,{ }^{*} \mathrm{P}<0.05$ vs. control, "P<0.05 vs. UTP $(125 \mu \mathrm{M})$. (B) U0126 failed to prevent the effect induced by UTP on 3- and 7-day-old cultures. Results are expressed as percentages with respect to GAPDH expression. Data represent the means $\pm \mathrm{SD}, \mathrm{n}=3,{ }^{*} \mathrm{P}<0.05$ vs. control, ${ }^{\sharp} \mathrm{P}<0.05$ vs. UTP $(125 \mu \mathrm{M})$.

SD rats. Second, in this previous study, dexamethasone was not added to the osteogenic medium during osteoblast differentiation (22). It has been noted that dexamethasone downregulates Runx2, a transcription factor required for osteoblast differentiation (39), and inhibits Wnt/ $\beta$-catenin, a signaling pathway involved in the osteoblast differentiation of mesenchymal progenitor cells (40). Third, the detection indices and methods used in these studies differed from those used in our research. Any one or a combination of these factors explains the differences in these studies.

The differentiation of BMSCs into the osteoblastic or adipogenic lineages is not an independent process: molecular components promoting one cell fate inhibit the mechanisms governing the differentiation of the alternative lineage $(5,41)$. This is also the case for UTP. In the present study, UTP increased the expression of adipogenic-related markers in a dose-dependent manner. Furthermore, the formation of lipid droplets, another specific characteristic of adipogenic differentiation, was also increased by UTP treatment. Consistent with our study, Ciciarello et al reported that extracellular UTP increased the mRNA expression of PPAR in human BMSCs (42). However, a previous study reported that ATP and adenine compounds, but not other nucleotides (UTP, UDP,
CTP, GTP, ITP and diadenosine tetraphosphate), stimulated lipogenesis in adipocytes (43). In this previous study, the lipogenesis of adipocytes derived from the epididymal fat pads of male Wistar rats was detected by measuring the incorporation of $\mathrm{D}-\left[3-{ }^{3} \mathrm{H}\right]$ glucose in toluene extractable lipids, but without mRNA or protein data on any key adipogenic related genes, such as PPAR $\gamma$. Adipogenesis consists of integrated cascades that involve several transcription factors. The initial step of adipogenesis is the lineage commitment of MSC followed by the expansion of preadipocytes. PPAR $\gamma$ is a critical component in adipogenesis, as indicated by the fact that loss of PPAR $\gamma$ expression in murine embryonic fibroblasts leads to a complete absence of adipogenic capacity (44). MSCs differentiate into adipocytes when they express PPAR $\gamma$, which enhances the expression of adipogenic genes (45). Although it is not clear whether the apparent discrepancy is a matter of the detection method or of the different cell types used in experiments, we consider that the results of qPCR and immunohistochemical staining in our study strongly indicate that UTP is a positive stimulus of adipogenesis in rat BMSCs.

UTP stimulates the P2Y2 receptor and, following degradation to UDP, also acts on the P2Y6 receptor (21). In this study, we demonstrated that UTP regulated the differentiation of 
BMSCs into adipogenic cells, but not osteoblasts by activating the $\mathrm{P} 2 \mathrm{Y} 2$ receptor rather than $\mathrm{P} 2 \mathrm{Y} 4$ or $\mathrm{P} 2 \mathrm{Y} 6$ receptors. Studies have previously reported the effects of $\mathrm{P} 2 \mathrm{Y}$ receptors on the osteogenic and adipogenic differentiation of BMSCs, with varying results. For example, Ciciarello et al reported that ATP stimulated adipogenic differentiation of human BMSCs, mainly acting through P2Y1 and P2Y4 subtypes (42). Conversely, adenosine resulting from ATP degradation increased BMSC osteogenic differentiation, by activating the A2B adenosine-specific receptor subtype (42). Zippel et al reported that ATP, but not UTP partially compensated for the potent inhibitory effects on matrix mineralization induced by suramin and PPADS (P2 receptor antagonists) in human BMSCs, indicating that $\mathrm{P} 2 \mathrm{Y} 2$ and $\mathrm{P} 2 \mathrm{Y} 4$ receptors had no effect on osteogenesis (18). UTP, but not ATP, partly compensated for the decrease in formation of lipid droplets induced by PPADS, thus suggesting the involvement of P2Y4 receptor (18). In these two studies, the authors used several agonists and antagonists of $\mathrm{P} 2$ receptors to identify which receptors were activated in the processes of osteogenic and adipogenic differentiation. Indeed, many of the $\mathrm{P} 2$ receptor subtypes are still lacking potent and selective synthetic agonists and antagonists. These reagents are considered effective stimulators and inhibitors of $\mathrm{P} 2$ receptors. Thus, to delineate the role of each $\mathrm{P} 2$ receptor in osteogenesis and adipogensis of BMSCs, several issues need to be addressed, including specific agonists and antagonists of P2 receptors, and gene knockout models.

In the present study, pharmacological approaches revealed that UTP enhanced the differentiation of BMSCs into adipocytes, but not osteoblasts by stimulating the ERK1/2 signaling pathway in a P2Y2R-dependent manner. In agreement with our data, it has been previously reported that the activation of P2Y2 receptors by extracellular nucleotides is responsible for the phosphorylation of ERK1/2 in osteoblasts. For example, Costessi et al reported that extracellular ATP and UTP stimulate the ERK1/2-dependent activation of the transcription factor Runx2 via the P2Y2 receptor in the osteoblast-like HOBIT cell line (46). Katz et al reported that P2Y2 receptor stimulation by ATP in osteoblasts sensitizes mechanical stress-activated calcium channels, leading to calcium influx and fast activation of the ERK1/2 and p38 MAPK pathways (47). However, in studies on MAPK signaling and its role in the differentiation of BMSCs, the ERK $1 / 2$ pathway is widely reported as a positive regulator of osteogenesis $(32,33,35,36)$ and a negative regulator of adipogenesis $(37,38)$. To investigate the differences between our observations and previous studies, in the present study we employed U0126, a MAPK inhibitor. Consistent with these studies, we observed that the inhibition of ERK1/2 activation by U0126 inhibited osteogenic-related gene expression, and enhanced adipogenic-related gene expression in 3- and 7-day-old cultures. However, U0126 significantly attenuated the effects of UTP on these genes at $24 \mathrm{~h}$ of incubation. Our study on ERK1/2 modulation by UTP showed that purinergic activation rapidly stimulated MAPK phosphorylation in BMSCs. UTP-induced ERK1/2 activation reached a peak at $5 \mathrm{~min}$ and was weaker at $60 \mathrm{~min}$. In view of this finding, we speculate that ERK1/2 is a branch or a feedback loop of the complex signaling pathways involved in the onset of differentiation of BMSCs. In other words, we suggest that UTP mediates the early stage of osteogenic and adipogenic differentiation of BMSCs via activation of the ERK1/2 signaling pathway. We believe that the reverse effect of ERK1/2 signaling may be a possible interpretation for contrary views widely reported in the literature and may provide new insight into the molecular regulation of the osteogenic differentiation of rat BMSCs. The exact downstream components of the signaling pathway remain unknown. Thus, we have great interest in researching them in future studies.

\section{Acknowledgements}

The present study was supported by the National Natural Science Foundation of China (grant no. 81301552).

\section{References}

1. Raisz LG: Pathogenesis of osteoporosis: concepts, conflicts, and prospects. J Clin Invest 115: 3318-3325, 2005.

2. Hess R, Pino AM, Ríos S, Fernández M and Rodríguez JP: High affinity leptin receptors are present in human mesenchymal stem cells (MSCs) derived from control and osteoporotic donors. J Cell Biochem 94: 50-57, 2005.

3. Dalle Carbonare L, Valenti MT, Zanatta M, Donatelli L and Lo Cascio V: Circulating mesenchymal stem cells with abnormal osteogenic differentiation in patients with osteoporosis. Arthritis Rheum 60: 3356-3365, 2009.

4. Egermann M, Heil P, Tami A, Ito K, Janicki P, Von Rechenberg B, Hofstetter W and Richards PJ: Influence of defective bone marrow osteogenesis on fracture repair in an experimental model of senile osteoporosis. J Orthop Res 28: 798-804, 2010.

5. Nuttall ME and Gimble JM: Controlling the balance between osteoblastogenesis and adipogenesis and the consequent therapeutic implications. Curr Opin Pharmacol 4: 290-294, 2004.

6. Post S, Abdallah BM, Bentzon JF and Kassem M: Demonstration of the presence of independent pre-osteoblastic and pre-adipocytic cell populations in bone marrow-derived mesenchymal stem cells. Bone 43: 32-39, 2008.

7. Barry FP and Murphy JM: Mesenchymal stem cells: clinical applications and biological characterization. Int J Biochem Cell Biol 36: 568-584, 2004.

8. Jiang Y, Jahagirdar BN, Reinhardt RL, Schwartz RE, Keene CD, Ortiz-Gonzalez XR, Reyes M, Lenvik T, Lund T, Blackstad M, et al: Pluripotency of mesenchymal stem cells derived from adult marrow. Nature 418: 41-49, 2002.

9. Maurin AC, Chavassieux PM, Frappart L, Delmas PD, Serre CM and Meunier PJ: Influence of mature adipocytes on osteoblast proliferation in human primary cocultures. Bone 26: 485-489, 2000.

10. Wan Y, Chong LW and Evans RM: PPAR-gamma regulates osteoclastogenesis in mice. Nat Med 13: 1496-1503, 2007.

11. Robling AG, Hinant FM, Burr DB and Turner CH: Improved bone structure and strength after long-term mechanical loading is greatest if loading is separated into short bouts. J Bone Miner Res 17: 1545-1554, 2002.

12. Duncan RL and Turner $\mathrm{CH}$ : Mechanotransduction and the functional response of bone to mechanical strain. Calcif Tissue Int 57: 344-358, 1995.

13. Hoebertz A, Arnett TR and Burnstock G: Regulation of bone resorption and formation by purines and pyrimidines. Trends Pharmacol Sci 24: 290-297, 2003.

14. Riddle RC, Taylor AF, Rogers JR and Donahue HJ: ATP release mediates fluid flow-induced proliferation of human bone marrow stromal cells. J Bone Miner Res 22: 589-600, 2007.

15. Rumney RM, Sunters A, Reilly GC and Gartland A: Application of multiple forms of mechanical loading to human osteoblasts reveals increased ATP release in response to fluid flow in 3D cultures and differential regulation of immediate early genes. J Biomech 45: 549-554, 2012.

16. Ferrari D, Gulinelli S and Salvestrini V, Lucchetti G, Zini R, Manfredini R, Caione L, Piacibello W, M Ciciarello et al: Purinergic stimulation of human mesenchymal stem cells potentiates their chemotactic response to CXCL12 and increases the homing capacity and production of proinflammatory cytokines. Exp Hematol 39: 360-374, 2011. 
17. Noronha-Matos JB, Costa MA, Magalhães-Cardoso MT, Ferreirinha F, Pelletier J, Freitas R, Neves JM, Sévigny J and Correia-de-Sá P: Role of ecto-NTPDases on UDP-sensitive $\mathrm{P} 2 \mathrm{Y}(6)$ receptor activation during osteogenic differentiation of primary bone marrow stromal cells from postmenopausal women. J Cell Physiol 227: 2694-2709, 2012.

18. Zippel N, Limbach CA, Ratajski N, Urban C, Luparello C, Pansky A, Kassack MU and Tobiasch E: Purinergic receptors influence the differentiation of human mesenchymal stem cells. Stem Cells Dev 21: 884-900, 2012.

19. Erlinge D and Burnstock G: $P 2$ receptors in cardiovascular regulation and disease. Purinergic Signal 4: 1-20, 2008.

20. Burnstock G: Purinergic signalling: past, present and future. Braz J Med Biol Res 42: 3-8, 2009.

21. Abbracchio MP, Burnstock G, Boeynaems JM, Barnard EA, Boyer JL, Kennedy C, Knight GE, Fumagalli M, Gachet C, Jacobson KA and Weisman GA: International Union of Pharmacology LVIII: update on the P2Y G protein-coupled nucleotide receptors: from molecular mechanisms and pathophysiology to therapy. Pharmacol Rev 58: 281-341, 2006.

22. Ayala-Peña VB, Scolaro LA and Santillán GE: ATP and UTP stimulate bone morphogenetic protein-2,-4 and -5 gene expression and mineralization by rat primary osteoblasts involving PI3K/AKT pathway. Exp Cell Res 319: 2028-2036, 2013.

23. Orriss IR, Utting JC, Brandao-Burch A, Colston K, Grubb BR, Burnstock $\mathrm{G}$ and Arnett TR: Extracellular nucleotides block bone mineralization in vitro: evidence for dual inhibitory mechanisms involving both $\mathrm{P} 2 \mathrm{Y} 2$ receptors and pyrophosphate. Endocrinology 148: 4208-4216, 2007.

24. Orriss IR, Knight GE, Ranasinghe S, Burnstock G and Arnett TR: Osteoblast responses to nucleotides increase during differentiation. Bone 39: 300-309, 2006.

25. Hoebertz A, Mahendran S, Burnstock G and Arnett TR: ATP and UTP at low concentrations strongly inhibit bone formation by osteoblasts: a novel role for the P2Y2 receptor in bone remodeling. J Cell Biochem 86: 413-419, 2002.

26. Lee SC, Vielhauer NS, Leaver EV and Pappone PA: Differential regulation of $\mathrm{ca}(2+)$ signaling and membrane trafficking by multiple p2 receptors in brown adipocytes. J Membr Biol 207: $131-142,2005$

27. Lee H, Jun DJ, Suh BC, Choi BH, Lee JH, Do MS, Suh BS, $\mathrm{Ha} \mathrm{H}$ and Kim KT: Dual roles of $\mathrm{P} 2$ purinergic receptors in insulin-stimulated leptin production and lipolysis in differentiated rat white adipocytes. J Biol Chem 280: 28556-28563, 2005.

28. Sreejit P, Dilip KB and Verma RS: Generation of mesenchymal stem cell lines from murine bone marrow. Cell Tissue Res 350: 55-68, 2012.

29. Barragán-Iglesias P, Mendoza-Garcés L, Pineda-Farias JB Solano-Olivares V, Rodríguez-Silverio J, Flores-Murrieta FJ, Granados-Soto V and Rocha-González HI: Participation of peripheral P2Y1, P2Y6 and P2Y11 receptors in formalin-induced inflammatory pain in rats. Pharmacol Biochem Behav 128: 23-32, 2015.

30. Rodrigues-Ribeiro R, Alvarenga EC, Calio ML, ParedesGamero EJ and Ferreira AT: Dual role of P2 receptors during osteoblast differentiation. Cell Biochem Biophys 71: 1225-1233, 2015.

31. Orriss IR, Knight GE, Utting JC, Taylor SE, Burnstock G and Arnett TR: Hypoxia stimulates vesicular ATP release from rat osteoblasts. J Cell Physiol 220: 155-162, 2009.

32. Yong Y, Ming ZD, Feng L, Chun ZW and Hua W: Electromagnetic fields promote osteogenesis of rat mesenchymal stem cells through the PKA and ERK1/2 pathways. J Tissue Eng Regen Med: Mar 16, 2014 (Epub ahead of print).
33. Li Y, Yan M, Wang Z, Zheng Y, Li J, Ma S, Liu G and Yu J: 17beta-estradiol promotes the odonto/osteogenic differentiation of stem cells from apical papilla via mitogen-activated protein kinase pathway. Stem Cell Res Ther 5: 125, 2014.

34. Xu FF, Zhu H, Li XM, Yang F, Chen JD, Tang B, Sun HG, Chu YN, Zheng RX, Liu YL, et al: Intercellular adhesion molecule-1 inhibits osteogenic differentiation of mesenchymal stem cells and impairs bio-scaffold-mediated bone regeneration in vivo. Tissue Eng Part A 20: 2768-2782, 2014.

35. Liu D, Yi C, Fong CC, Jin Q, Wang Z, Yu WK, Sun D, Zhao J and Yang M: Activation of multiple signaling pathways during the differentiation of mesenchymal stem cells cultured in a silicon nanowire microenvironment. Nanomedicine (Lond) 10: 1153-1163, 2014

36. Yu Y, Wang L, Yu J, Lei G, Yan M, Smith G, Cooper PR, Tang C, Zhang $\mathrm{G}$ and Smith AJ: Dentin matrix proteins (DMPs) enhance differentiation of BMMSCs via ERK and P38 MAPK pathways. Cell Tissue Res 356: 171-182, 2014

37. Hashimoto R, Katoh Y, Miyamoto Y, Itoh S, Daida H, Nakazato Y and Okada T: Increased extracellular and intracellular $\mathrm{Ca}^{2+}$ lead to adipocyte accumulation in bone marrow stromal cells by different mechanisms. Biochem Biophys Res Commun 457: 647-652, 2015.

38. Kusuyama J, Bandow K, Shamoto M, Kakimoto K, Ohnishi T and Matsuguchi T: Low intensity pulsed ultrasound (LIPUS) influences the multilineage differentiation of mesenchymal stem and progenitor cell lines through ROCK-Cot/Tpl2-MEK-ERK signaling pathway. J Biol Chem 289: 10330-10344, 2014.

39. Zhang YY, Li X, Qian SW, Guo L, Huang HY, He Q, Liu Y, Ma CG and Tang QQ: Down-regulation of type I Runx 2 mediated by dexamethasone is required for 3T3-L1 adipogenesis. Mol Endocrinol 26: 798-808, 2012.

40. Naito M, Omoteyama K, Mikami Y, Takahashi T and Takagi M: Inhibition of $\mathrm{Wnt} / \beta$-catenin signaling by dexamethasone promotes adipocyte differentiation in mesenchymal progenitor cells, ROB-C26. Histochem Cell Biol 138: 833-845, 2012.

41. Menuki K, Mori T, Sakai A, Sakuma M, Okimoto N, Shimizu Y, Kunugita $\mathrm{N}$ and Nakamura T: Climbing exercise enhances osteoblast differentiation and inhibits adipogenic differentiation with high expression of PTH/PTHrP receptor in bone marrow cells. Bone 43: 613-620, 2008.

42. Ciciarello M, Zini R, Rossi L, Salvestrini V, Ferrari D, Manfredini R and Lemoli RM: Extracellular purines promote the differentiation of human bone marrow-derived mesenchymal stem cells to the osteogenic and adipogenic lineages. Stem Cells Dev 22: 1097-1111, 2013.

43. Schödel J, Weise I, Klinger R and Schmidt M: Stimulation of lipogenesis in rat adipocytes by ATP, a ligand for P2-receptors. Biochem Biophys Res Commun 321: 767-773, 2004.

44. Kubota N, Terauchi Y, Miki H, Tamemoto H, Yamauchi T, Komeda K, Satoh S, Nakano R, Ishii C, Sugiyama T, et al: PPAR gamma mediates high-fat diet-induced adipocyte hypertrophy and insulin resistance. Mol Cell 4: 597-609, 1999.

45. Kawai $M$ and Rosen CJ: PPAR $\gamma$ : a circadian transcription factor in adipogenesis and osteogenesis. Nat Rev Endocrinol 6: 629-636, 2010

46. Costessi A, Pines A, D'Andrea P, Romanello M, Damante G, Cesaratto L, Quadrifoglio F, Moro L and Tell G: Extracellular nucleotides activate Runx 2 in the osteoblast-like HOBIT cell line: a possible molecular link between mechanical stress and osteoblasts' response. Bone 36: 418-432, 2005.

47. Katz S, Boland R and Santillán G: Modulation of ERK 1/2 and p38 MAPK signaling pathways by ATP in osteoblasts: involvement of mechanical stress-activated calcium influx, PKC and Src activation. Int J Biochem Cell Biol 38: 2082-2091, 2006. 